\title{
Demographic Changes in Germany up to 2060 - Consequences for Blood Donation
}

\author{
Manfred Ehling Olga Pötzsch \\ Statistisches Bundesamt, Wiesbaden, Germany
}

\author{
Keywords \\ Demographic factor - Blood donation . \\ Population projection - Aging · Life expectancy . \\ Fertility
}

\section{Summary}

This paper outlines the results of a most recent model calculation regarding the structure and development of Germany's population by 2060 with the aim to provide basic demographic data for the future provision of blood components to the population. Firstly, the paper describes the assumptions on fertility, life expectancy and Germany's balance of immigration and emigration which formed the basis for the projection. The following part discusses the results, quantifies future changes in the size and age structure of Germany's population, and illustrates the effects of demographic trends which can be identified from today's point of view. The number of potential blood donors will decline in absolute and relative terms (related to the total population and the age group of 'non-donors') in the future. This holds true for both the age bracket of 18 to 68 years and the alternatively chosen age group of 17 to 70 years. Depending on the variant, the population of blood donation age will decrease by one quarter to one third until 2060.

\section{Introduction}

This paper outlines the results of a most recent model calculation regarding the structure and development of Germany's population by 2060 with the aim to provide basic demographic

\author{
Schlüsselwörter \\ Demographischer Faktor · Blutspende . \\ Bevölkerungsvorausberechnungen · Alterung · \\ Lebenserwartung · Fertilität
}

\section{Zusammenfassung}

In dem Aufsatz wird eine aktuelle Modellrechnung über die Struktur und Entwicklung der Bevölkerung in Deutschland bis 2060 vorgelegt, um demographische Basisdaten für die künftige Versorgung der Bevölkerung mit Blutkomponenten zu liefern. Zuerst werden die Annahmen zur Geburtenhäufigkeit, zur Lebenserwartung und zum Saldo der Zuzüge nach und der Fortzüge aus Deutschland, auf denen die Vorausberechnung beruht, erläutert. Im Ergebnisteil werden die künftigen Veränderungen in der Größe und im Altersaufbau der Bevölkerung Deutschlands quantifiziert und die Auswirkungen der aus heutiger Sicht absehbaren demografischen Entwicklungen aufgezeigt. Die Altergruppe der potenziellen Blutspender wird künftig sowohl bei der Abgrenzung von 18 bis 68 Jahren als auch bei der alternativ gerechneten Abgrenzung von 17 bis 70 Jahren absolut und relativ - in Bezug auf die Gesamtbevölkerung und auf die Altersgruppe der "Nichtspender» - abnehmen. Je nach Variante wird die Bevölkerung in blutspendefähigem Alter bis zum Jahr 2060 um ein Viertel bis zu einem Drittel schrumpfen.

data for the future provision of blood components to the population. In this respect, our society faces a double challenge. On the one hand, the age of patients will increase so that more blood components will be required to treat their diseases. On the other hand, the number of people aged between

\begin{tabular}{ll}
\hline KARGER & $\oplus$ 2010 S. Karger GmbH, Freiburg \\
Fax +497614520714 & Accessible online at: \\
$\begin{array}{l}\text { Information@Karger.de } \\
\text { www.karger.com }\end{array}$ & www.karger.com/tmh
\end{tabular}


18 and 68 years who are currently be considered as potential blood donors will tend to decline.

Based on the results of the 12th coordinated population projection of the Federal Statistical Office [1], this paper shows how, under certain assumptions, the population size and structure will develop until 2060. The population projection comprises a total of 12 variants obtained by combining different assumptions on fertility, life expectancy and Germany's balance of immigration and emigration. Two variants defining the upper and lower limits of what we call a 'medium' population were used to approach the subject of this paper. As a result of the relevant evaluation, basic demographic data were obtained for an outlook focusing on the future provision of blood components to the population.

\section{Model and Assumptions}

The Federal Statistical Office used a macrosimulation model for its 12th coordinated population projection whose operation was based on the total population in a breakdown by birth year and sex. The relevant data on all cohorts living in the base year of the population projection (2008) were updated on a year-by-year basis using age- and sex-specific transition probabilities and frequencies. The children of those cohorts formed the new cohorts. The model applied was based on the internationally recognised cohort component method [2] including deterministic assumptions. The components used for updating purposes included the demographic variables of fertility, mortality and migration. Detailed assumptions were made regarding the development of the components in the projection period. They were based on both analyses of the trends of these components over time and across the German Länder and on hypotheses regarding future trends that could be identified from a current perspective.

As the increasing distance from the base date makes it more and more difficult to predict the components' development, long-term population projections have a model character. Calculating several scenarios makes it possible to illustrate the scope of potential change resulting from alternative assumptions on the development of the determinant components.

\section{Fertility}

The development of births depends on the reproductive behaviour of people of the relevant age. In statistical terms, this behaviour is reflected, above all, by the number of children per woman and the age at which women have children.

For several decades, fertility has been at a low level in Germany. The number of children born has not been sufficient to replace the generation of their parents. In order to reach a situation in which the population fully replenishes itself, each woman must give birth to 2.1 children, taking into account a low mortality of potential mothers [3]. The fertility behaviour is characterised by several long-term trends: The average age of first-time mothers has increased and continues to rise. The average number of children per mother is relatively stable, though the share of mothers in all women declines at the same time due to increasing childlessness. As a result, the average number of children born to the women of an age cohort shows a decline over time.

Three assumptions regarding the future development (which are described by different total fertility rates below) were derived from the above trends. Although all three assumptions consider the long-term development, each of them emphasises different aspects [4].

The main assumption is that the major trends will continue until 2020. Afterwards the conditions are assumed to remain stable. Compared to the base year, the following changes will be expected: An increasing number of women will have their first child at an age above 30 , and the fertility rates among younger women will continue to decline. Postponing the birth of children to a later age will result in a slightly falling proportion of mothers having three or more children. Consequently, the average number of children per mother will decline, too. Compared to the current rate of childlessness (about $20 \%$ for women in their mid-forties), the proportion of women without children will slightly increase.

Under these conditions, the total fertility rate related to the calendar years will remain at the level of 1.4 children per woman. The completed fertility of female cohorts will decrease to the same level in the long run.

The second assumption is that the number of children per woman will slightly rise to 1.6 by 2025 . Afterwards, the fertility will remain unchanged.

The third assumption is that the number of children per woman will slightly fall to 1.2 by 2060 .

All three assumptions imply that the women's age at birth will increase.

\section{Mortality}

For more than 130 years we have witnessed a continuous fall in mortality and a rise in life expectancy in Germany. This development is largely attributable to progress in medical care, better hygiene and nutrition, improvements in the housing situation, and to better conditions of work and increasing material well-being. At the end of the 19th century mortality began to fall strongly, first of all, in respect of infants and children. In the second half of the last century the mortality of older people also fell considerably [5].

Since the foundation of the German Reich in 1871, mortality rates and average life expectancies have been recorded regularly, using what are called period life tables. The average life expectancy shows how many years new-born male or female children can expect to live if the population's mortality risk observed at a given time continues to apply during the age years of their whole life. As for persons who have reached a certain age, e.g. 65 years, the number of further years they 
can expect to live is expressed as the average further life expectancy.

In the light of past developments in Germany and the evolution of life expectancy in other developed countries of the world, it is assumed that improvements in living conditions compared to those of former generations and a further enhancement of the medical care system will lead to a further rise in life expectancy in Germany in the years to come. However, the evolution of life expectancy will be increasingly determined by the falling mortality of older age groups in the future. As the mortality risk is already very low in the young age groups, improvements in living conditions would only have a relatively small effect on the development of total life expectancy.

With the aim to define the assumptions, the mortality risks of men and women were examined in each age cohort in order to identify both long-term and short-term trends in the past and potential improvements in the future. The fact that the mortality risk has declined continuously made it easier to derive the relevant trends [6]. Both a long-term trend for the period since 1871 and a short-term trend since 1970 were determined for each age group. The short-term trend takes into account the clear reduction in the mortality risk of people aged 60 years and older during the last 35 years. This decline has been particularly due to medical progress regarding diseases of the circulatory system. Furthermore, the short-term trend shows that the gap in life expectancy between men and women is reducing.

According to the base assumption, the average life expectancy at birth will be 85.0 years for men and 89.2 years for women, resulting in an increase of 7.8 and 6.8 years, respectively, on the 2006/2008 level of life expectancy in Germany. The difference in life expectancy between men and women will fall from 5.2 to 4.2 years by 2060 . 65-year-old men and women of the same age can expect to live 22.3 and 25.5 more years, respectively. This is about 5 years more than in $2006 / 2008$. This assumption is based on a combination of the short-term trend observed since 1970 and the long-term trend recorded since 1871 .

In a high assumption on life expectancy, men can expect to live (from birth) on average for 87.7 years and women for 91.2 years. That means that men will live 10.6 years and women 8.8 years longer than in 2006/2008. The difference in life expectancy between men and women will fall from 5.2 to 3.5 years. 65-year-old men and women can expect to live 24.7 and 27.4 more years, respectively. The assumption of high life expectancy is based on the trends observed since 1970. A necessary condition for that assumption is that the improvements in the medical care system and the resulting reduction in the mortality risk of older age groups will proceed largely along the same lines until 2060 as during the last 35 years.

\section{Migration}

In addition to births and deaths there is another important factor which influences population trends in Germany. It is the movement of people across the border of the country, which is referred to as external migration. But unlike fertility and life expectancy, net migration trends can hardly be derived from past data. On the one hand, net migration depends on the potential number of migrants leaving their countries of origin for certain political, economic, demographic and even ecological reasons [7]. On the other hand, it is influenced by Germany's migration policy and the extent to which Germany is perceived as a country of destination that is attractive in socio-economic terms.

However, the migration trends of the past show some tendencies which can definitely be considered in the assumptions on future net migration. They concern, above all, the longand medium-term level of immigration and emigration, differences in the migration patterns of German and foreign citizens, and specific characteristics of the age structure.

With the exception of a few years, net migration has been positive in Germany. Its annual total ranged between 129,000 and 354,000 persons in the periods under review. In the past 5 years or so, the balance of immigration and emigration has declined markedly. This has been due to, on the one hand, an increase in the number of German emigrants and, on the other, the negligible inflow of ethnic Germans and lessening number of foreign immigrants. Migration figures are not included for 2008 because the volume of emigration determined for that year was affected by a wide range of adjustments made in the population register.

The two assumptions made in the context of the 12th coordinated population projection indicate a gradual growth of annual net migration to 100,000 persons from 2014 (assumption W1) on the one hand and to 200,000 persons from 2020 (assumption W2) on the other. These assumptions are in line with long-term averages.

At present, the migration balance of the German population is negative. It is assumed however that the negative trend will decline and finally almost level off as the number of young people and, consequently, the total of German emigrants will decrease in the future.

The temporarily very low migration balance of foreigners, which is partly attributable to the adjustments made in the population register in the context of introducing a tax identification code, is expected to rise quickly again. It is assumed that immigration levels will be boosted slightly from 2011 when in the German labour market, too, the free movement of labour will be applied to workers from the new Member States that joined the European Union in 2004.

However, assuming - from today's perspective - a very high level of annual net migration near the upper limit of the range within which net migration might vary in the future seems to be advisable, too. An increase in the number of people (above all foreigners) immigrating into Germany will be as likely as a slow-down in migration flows. The actual development will be largely determined by both demographic processes in Germany and world-wide trends. The current 
Table 1. Overview of 12 variants of the 12 th coordinated population projection

\begin{tabular}{|c|c|c|c|}
\hline \multirow[t]{2}{*}{ Life expectancy of new-born children in 2060 , males/females, years } & \multicolumn{3}{|c|}{ Total fertility rate (children per woman) } \\
\hline & nearly constant at $1.4(\mathrm{G} 1)$ & $\begin{array}{l}\text { slightly rising, } \\
\text { from 2025: } 1.6(\mathrm{G} 2)\end{array}$ & $\begin{array}{l}\text { long-term decline } \\
\text { 2060: } 1.2 \text { (G3) }\end{array}$ \\
\hline \multicolumn{4}{|c|}{ Annual balance of external migration: gradual increase to an annual net migration of 100,000 people from 2014 (W1) } \\
\hline $85.0 / 89.2$ base assumption (L1) & $\begin{array}{l}\text { variant } 1-W 1 \text { 'medium' } \\
\text { population, lower limit }\end{array}$ & variant 3-W1 & variant 5-W1 \\
\hline \multicolumn{4}{|c|}{ Annual balance of external migration: gradual increase to an annual net migration of 200,000 people from 2020 (W2) } \\
\hline 85.0/89.2 base assumption (L1) & $\begin{array}{l}\text { variant } 1-W 2 \text { 'medium' } \\
\text { population, upper limit }\end{array}$ & variant 3-W2 & variant $5-\mathrm{W} 2$ \\
\hline 87.7/91.2 high increase (L2) & variant $2-\mathrm{W} 2$ & variant $4-\mathrm{W} 2$ & variant $6-\mathrm{W} 2$ \\
\hline
\end{tabular}

economic crisis will possibly lead to a short-term rise in unemployment and, consequently, a temporary decline in the demand for labour. However, the extent to which the working-age population will shrink and age in Germany will be by far more severe than in its neighbouring countries. Under these circumstances, Germany would certainly be forced to raise its attractiveness in the competition for young workers. This, in turn, could lead to changes in current migration flows and result in a higher number of migrants moving to Germany.

Furthermore, the level of potential immigration from other regions in the world will continue to be high. The population in Asian and African countries will be both young and growing over the next few decades. Also, the effects of global climate warming which, according to recent estimates, would be less intense in Central Europe than in the other continents, could intensify immigration flows due to 'push' factors of migration in the regions of origin [8].

Actual migration levels will certainly continue to be subject to great variation so that the values assumed should only be interpreted as long-term averages. The assumptions that longterm annual net migration will be either 100,000 or 200,000 persons define the limits of a range within which migration processes could be expected to develop in the future.

\section{Population Trends in the Course of the Next 50 Years}

The total of 12 variants of the 12th coordinated population projection are obtained by combining the assumptions outlined above. For better illustration, the focus of this paper is on two of the variants which define the lower and upper limits of a 'medium' population. They combine assumptions of a nearly constant total fertility rate (1.4 children per woman) and a moderate increase in life expectancy (base assumption) with the two assumptions regarding net migration $(100,000$ or 200,000 persons per year). These two variants define the limits of a range within which the population size and age structure will develop, provided the demographic trends that can be identified today will continue (table 1).

In addition to the three demographic components, the current age structure of the population will impact the demographic development for a long time. A relatively large number of middle-aged people and few young people today will result in a relatively large number of older people and few people of middle age in the next few decades. This age-structure effect will lead to serious changes already in the next 10-20 years.

\section{Shrinking Population}

Germany's population has declined since 2003 (fig. 1). This decline will continue and even accelerate. In late 2008, about 82 million people lived in Germany. In 2060, their number will range between 65 million (lower limit of the 'medium' population) and 70 million (upper limit of the 'medium' population).

The population is dwindling because the number of deaths increasingly exceeds the number of births. Net immigration, which is defined as the positive difference between immigration into and emigration from Germany, cannot close this gap. As the low fertility rate of about 1.4 children per woman has been relatively constant for more than 30 years and is expected to remain largely unchanged in the future, every new generation will be smaller by one third compared to the generation of its parents. The number of births will thus decline continuously. In 2060, the number of deaths will presumably overtake the number of births by about 527,000-553,000.

\section{Changes in the Age Structure}

Both the declining number of births and the ageing of the large middle-aged cohorts cause significant changes in the age structure of the population. For a long time, the current population structure has deviated from the 'classic' population pyramid shape where children represent the strongest cohorts and the older cohorts gradually decrease in size as a result of increasing mortality (fig. 2). Today Germany's population 
Fig. 1. Population figures from 1950 to 2060; from 2009 results of the 12th coordinated population projection.

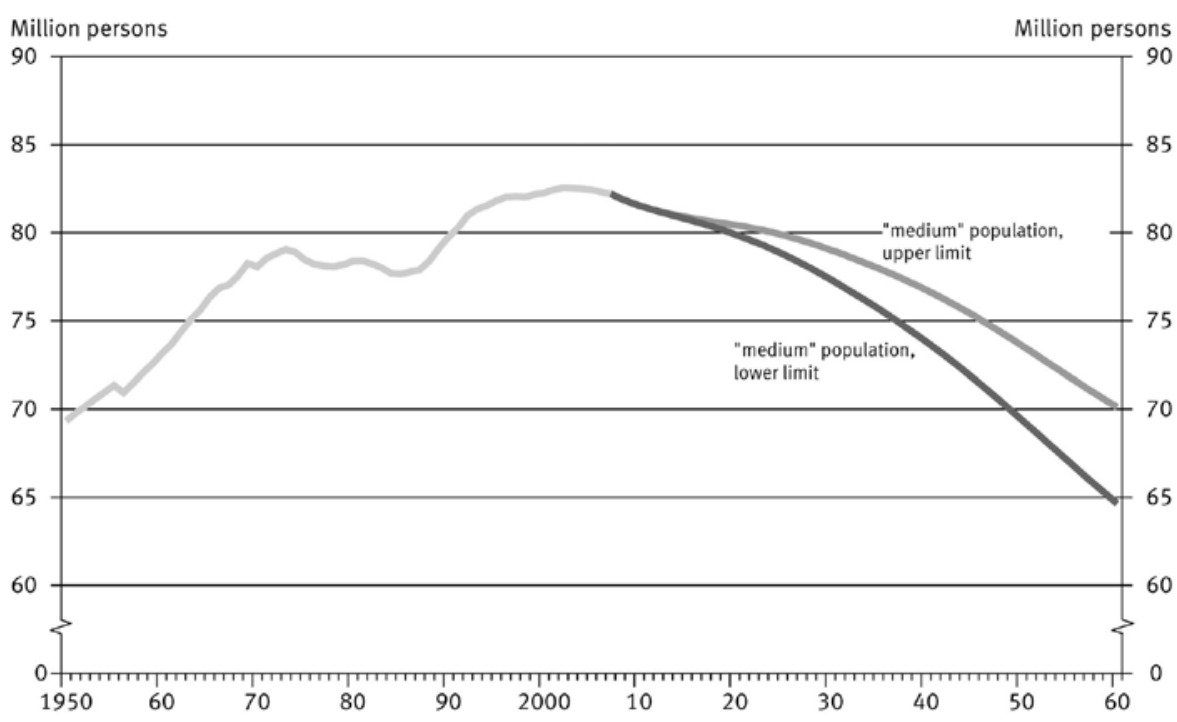

structure resembles a 'dishevelled fir tree', rather than a pyramid. The middle-aged cohorts are particularly large while the groups of older and younger people are smaller. By 2060, the large birth cohorts will move further upward, become sparser and will finally be replaced by smaller cohorts. At the same time, the relations between the different age groups will change significantly (table 2 ).

Today, children and young people under 20 years of age account for $19 \%$ of the population. The proportion of people aged 20 to under 65 years is $61 \%$, while that of seniors aged 65 and older amounts to $20 \%$ (fig. 3). In accordance with the variant projection for the 'medium' population (lower limit), every third person (34\%) will be at least 65 years old in 2060 and the number of 70-year-olds will be twice the number of new-born children.

The ageing process is especially reflected by the number of seniors aged 80 and more. In 2008, a total of about 4 million people in Germany were 80 years of age or older. They accounted for $5 \%$ of the population. Their number will continuously increase to reach an all-time high of more than 10 million in 2050. Between 2050 and 2060, the number of the oldest seniors will decline to 9 million. Hence $14 \%$ of the population (i.e. every 7 th person) can be expected to be 80 years old or older in 50 years' time. The number of people aged under 20 years, which totals about 16 million today, will decline to some 10 million by 2060 . This will be $16 \%$ of the population. Thus the number of young people aged under 20 will exceed the number of people aged 80 and above by not more than about 1 million in 2060.

Noticeable changes in the age structure of Germany's population will be observed already in the next decade. As shown in table 2, particularly the groups of people aged 50-65 years $(+24 \%)$ and 80 years and older $(+48 \%)$ will increase in size by 2020. The number of those aged under 50 will however decline $(-16 \%)$. The population aged 30 to under 50 alone will

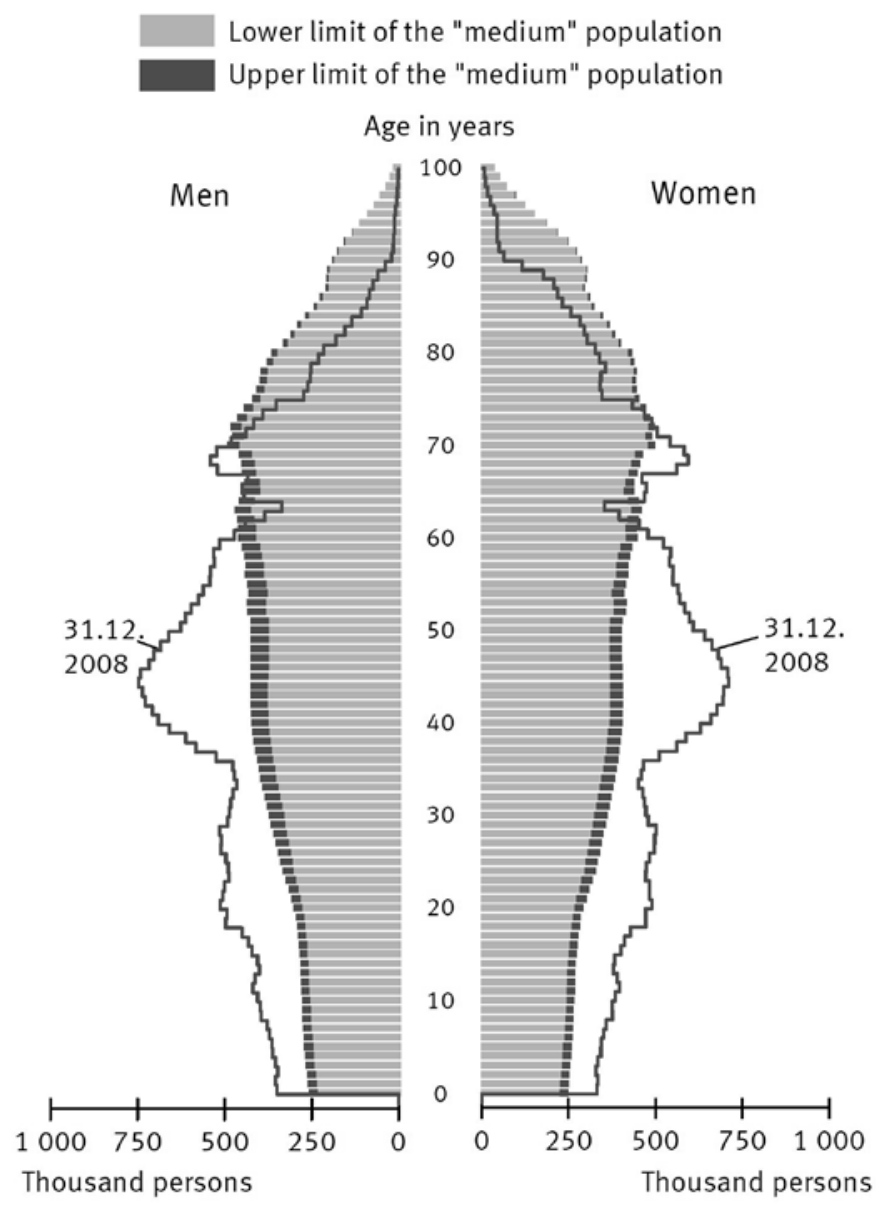

Fig. 2. Age structure of the population in Germany on December 31, 2008 and on December 31, 2060.

shrink by about 4 million (-18\%) (lower limit of the 'medium' population).

The median age of the population will increase rapidly due to the above changes. Today those aged 43 years are in the 
Table 2. Population by age groups, 2008, 2020 and 2060

\begin{tabular}{|c|c|c|c|c|c|c|c|c|c|}
\hline & \multirow[t]{3}{*}{2008} & \multicolumn{8}{|c|}{ 'Medium' population } \\
\hline & & \multicolumn{4}{|l|}{2020} & \multicolumn{4}{|l|}{2060} \\
\hline & & $\begin{array}{l}\text { lower } \\
\text { limit }\end{array}$ & $\begin{array}{l}\text { change on } \\
2008\end{array}$ & $\begin{array}{l}\text { upper } \\
\text { limit }\end{array}$ & $\begin{array}{l}\text { change on } \\
2008\end{array}$ & $\begin{array}{l}\text { lower } \\
\text { limit }\end{array}$ & $\begin{array}{l}\text { change on } \\
2008\end{array}$ & $\begin{array}{l}\text { upper } \\
\text { limit }\end{array}$ & $\begin{array}{l}\text { change on } \\
2008\end{array}$ \\
\hline \multicolumn{10}{|l|}{ Million persons } \\
\hline 0 to under 20 years & 15.6 & 13.6 & -2.0 & 13.7 & -1.9 & 10.1 & -5.5 & 11.0 & -4.6 \\
\hline 20 to under 30 years & 9.9 & 8.5 & -1.3 & 8.7 & -1.2 & 6.1 & -3.8 & 6.7 & -3.2 \\
\hline 30 to under 50 years & 24.3 & 19.8 & -4.4 & 20.1 & -4.2 & 14.6 & -9.7 & 16.3 & -8.0 \\
\hline 50 to under 65 years & 15.5 & 19.2 & 3.7 & 19.3 & 3.8 & 11.9 & -3.6 & 13.2 & -2.3 \\
\hline 65 to under 80 years & 12.7 & 12.6 & 0.0 & 12.7 & 0.0 & 12.9 & 0.3 & 13.7 & 1.0 \\
\hline 80 years and older & 4.1 & 6.0 & 1.9 & 6.0 & 2.0 & 9.0 & 5.0 & 9.2 & 5.2 \\
\hline Total & 82.0 & 79.9 & -2.1 & 80.4 & -1.6 & 64.7 & -17.4 & 70.1 & -11.9 \\
\hline \multicolumn{10}{|l|}{ Percent } \\
\hline 0 to under 20 years & 19 & 17 & -13 & 17 & -12 & 16 & -35 & 16 & -29 \\
\hline 20 to under 30 years & 12 & 11 & -14 & 11 & -12 & 9 & -38 & 10 & -32 \\
\hline 30 to under 50 years & 30 & 25 & -18 & 25 & -17 & 23 & -40 & 23 & -33 \\
\hline 50 to under 65 years & 19 & 24 & 24 & 24 & 24 & 18 & -23 & 19 & -15 \\
\hline 65 to under 80 years & 15 & 16 & 0 & 16 & 0 & 20 & 2 & 19 & 8 \\
\hline 80 years and older & 5 & 8 & 48 & 7 & 48 & 14 & 123 & 13 & 128 \\
\hline Total & 100 & 100 & -3 & 100 & -2 & 100 & -21 & 100 & -15 \\
\hline
\end{tabular}

very middle of the age distribution of the population. By the mid-2040s, the median age will rise by 9 years so that about half of the population will be older than 52 years between 2045 and 2060 (lower limit of the 'medium' population).

\section{Age Group of Potential Blood Donors}

The population of blood donation age will be particularly affected by shrinking and ageing. In the context of this paper, age brackets of 18 to 68 and alternatively of 17 to 70 years are considered for blood donation. As shown in table 3, the relative size of these two potential blood donor groups will be diminished by $-33.5 \%$ and $-32.9 \%$ between 2008 and 2060 , assuming an annual net migration of 100,000 persons. If net migration is larger, i.e. 200,000 per year, the decline of the two potential blood donor groups would amount to $-26.3 \%$ and $-26.8 \%$, respectively.

The shrinking process will start slowly and then accelerate after 2015 (fig. 4). Today, the age group of 18- to 68-year-olds comprises a total of 55.6 million people. Their number will decrease by 1.4 million until 2013 and remain at a level of approximately 54 million until 2018. Afterwards, a process of continuous reduction will start and continue until the end of the 2030s. In 2040, the number of 18- to 68-year-olds will range between 43.1 million (assuming an annual net migration of 100,000 persons) and 45.4 million (assuming an annual net migration of 200,000 persons) and hence be 22 or $18 \%$ below 2008 levels. After a short period of stabilisation, the size of this age group will continue to decline by 2060 , though at a slightly slower pace. A higher immigration level, as assumed
Fig. 3. Population by age groups.

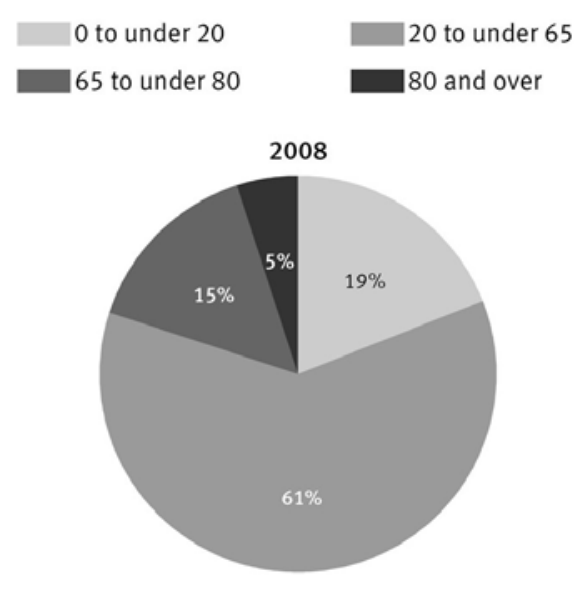

12th coordinated population projection, lower limit of the "medium" population

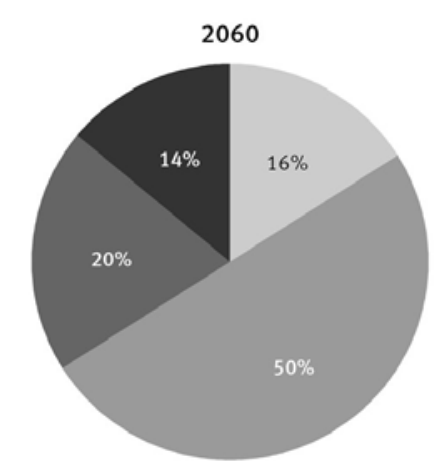


Table 3. Development of the age groups of potential blood donors*

\begin{tabular}{|c|c|c|c|c|c|c|c|c|}
\hline & \multicolumn{4}{|c|}{ Million persons } & \multicolumn{4}{|c|}{ Percentage change on 2008} \\
\hline & \multicolumn{2}{|c|}{ 18- to 68 -year-olds } & \multicolumn{2}{|c|}{17 - to 70 -year-olds } & \multicolumn{2}{|c|}{ 18- to 68 -year-olds } & \multicolumn{2}{|c|}{17 - to 70 -year-olds } \\
\hline & variant $1-\mathrm{W} 1$ & variant $1-\mathrm{W} 2$ & variant $1-\mathrm{W} 1$ & variant $1-\mathrm{W} 2$ & variant $1-\mathrm{W} 1$ & variant $1-\mathrm{W} 2$ & variant $1-\mathrm{W} 1$ & variant $1-\mathrm{W} 2$ \\
\hline 2008 & 55.6 & 55.6 & 58.6 & 58.6 & & & & \\
\hline 2015 & 54.3 & 54.4 & 56.5 & 56.6 & -2.3 & -2.2 & -3.7 & -3.5 \\
\hline 2020 & 53.2 & 53.6 & 55.8 & 56.3 & -4.4 & -3.6 & -4.8 & -4.1 \\
\hline 2025 & 51.3 & 52.2 & 54.0 & 54.9 & -7.8 & -6.2 & -7.8 & -6.3 \\
\hline 2030 & 48.7 & 50.0 & 51.7 & 53.1 & -12.5 & -10.1 & -11.8 & -9.4 \\
\hline 2035 & 45.5 & 47.3 & 48.7 & 50.5 & -18.2 & -14.9 & -17.0 & -13.8 \\
\hline 2040 & 43.1 & 45.4 & 45.9 & 48.2 & -22.4 & -18.3 & -21.8 & -17.8 \\
\hline 2045 & 42.1 & 44.8 & 44.3 & 47.1 & -24.4 & -19.5 & -24.4 & -19.6 \\
\hline 2050 & 40.6 & 43.8 & 43.0 & 46.3 & -27.0 & -21.3 & -26.7 & -21.0 \\
\hline 2055 & 38.9 & 42.5 & 41.3 & 45.0 & -30.1 & -23.6 & -29.6 & -23.2 \\
\hline 2060 & 37.0 & 41.0 & 39.3 & 43.5 & -33.5 & -26.3 & -32.9 & -25.8 \\
\hline
\end{tabular}

*From 2015 results of the 12 th coordinated population projection.

Fig. 4. Population in the blood donation age; from 2009 results of the 12 th coordinated population projection.

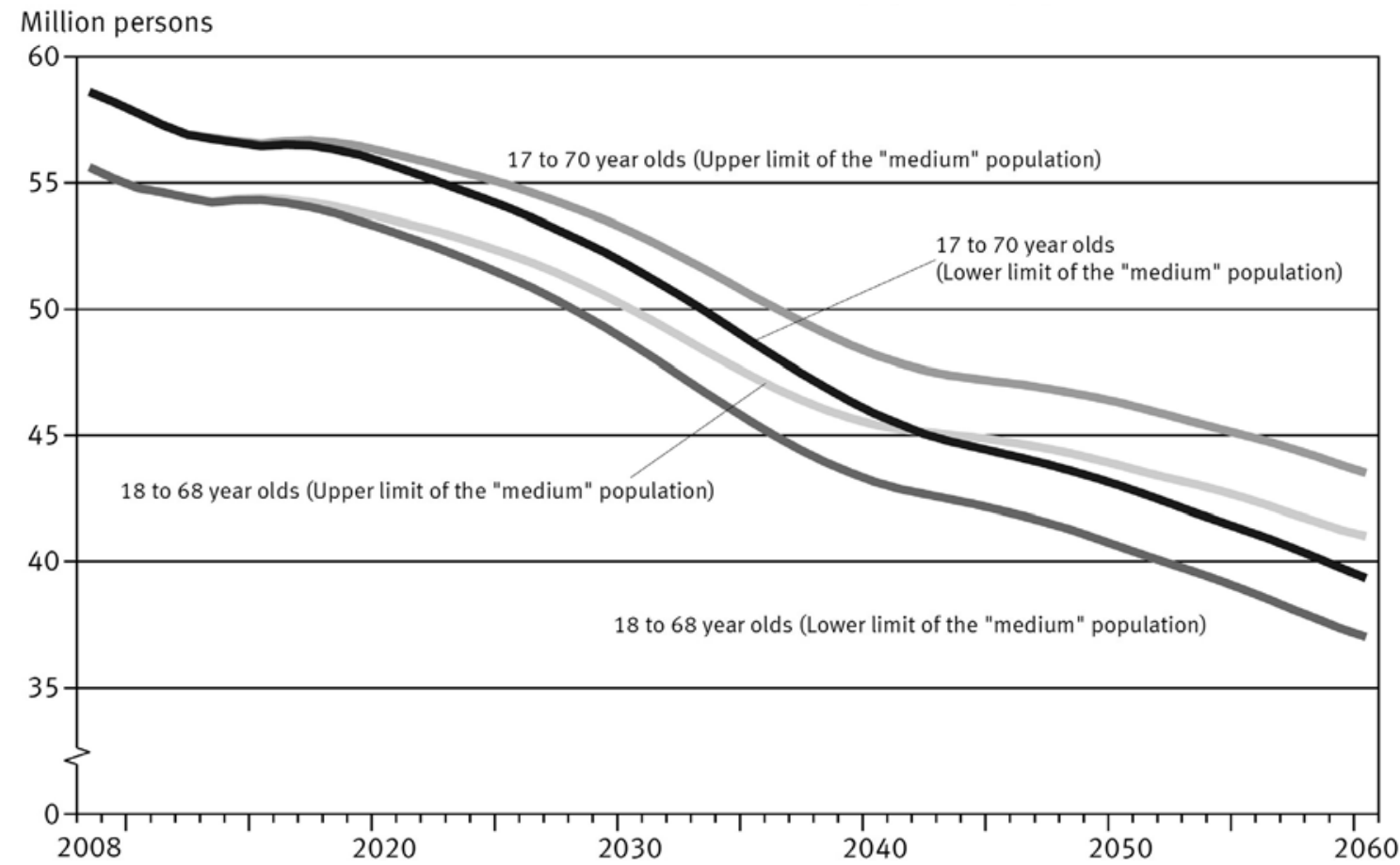

in variant $1-\mathrm{W} 2$, would have a particularly strong impact during that period. If an average 200,000 persons immigrated into Germany every year between 2040 and 2060, not less than 41 million people belonged to the group of 18 - to 68 -year-olds in 2060. If the number of immigrants were less, i.e. 100,000 per year, the age group would comprise just under 37 million people.

If the age bracket of potential blood donors is shifted from between 18 and 68 years to between 17 and 70 years, the new age group will decrease almost as quickly in the future, but the total of persons included will be larger. In 2008, the number of 17 - to 70 -year-olds amounted to 58.6 million. Be- tween 2020 und 2022, the number of people in that age group will still equal the current number of persons in the age group of 18 to 68 years (about 56 million).

Today, the difference between the two age groups totals 3 million people. Due to the different sizes of the cohorts which will move into or out of the relevant age, the difference between the two age groups will vary over time. Until 2015, the gap will narrow to 2 million. Afterwards, it will widen and reach again the level of about 3 million between 2028 and 2038. At the beginning of the 2040s, the difference between the two groups will decrease again and amount to slightly more than 2 million persons by 2060 (table 3). 
Fig. 5. Population by age groups related to blood donation age; from 2009 results of the 12 th coordinated population projection. Variant 1-W1 (lower limit of the 'medium' population).

\section{Million persons}

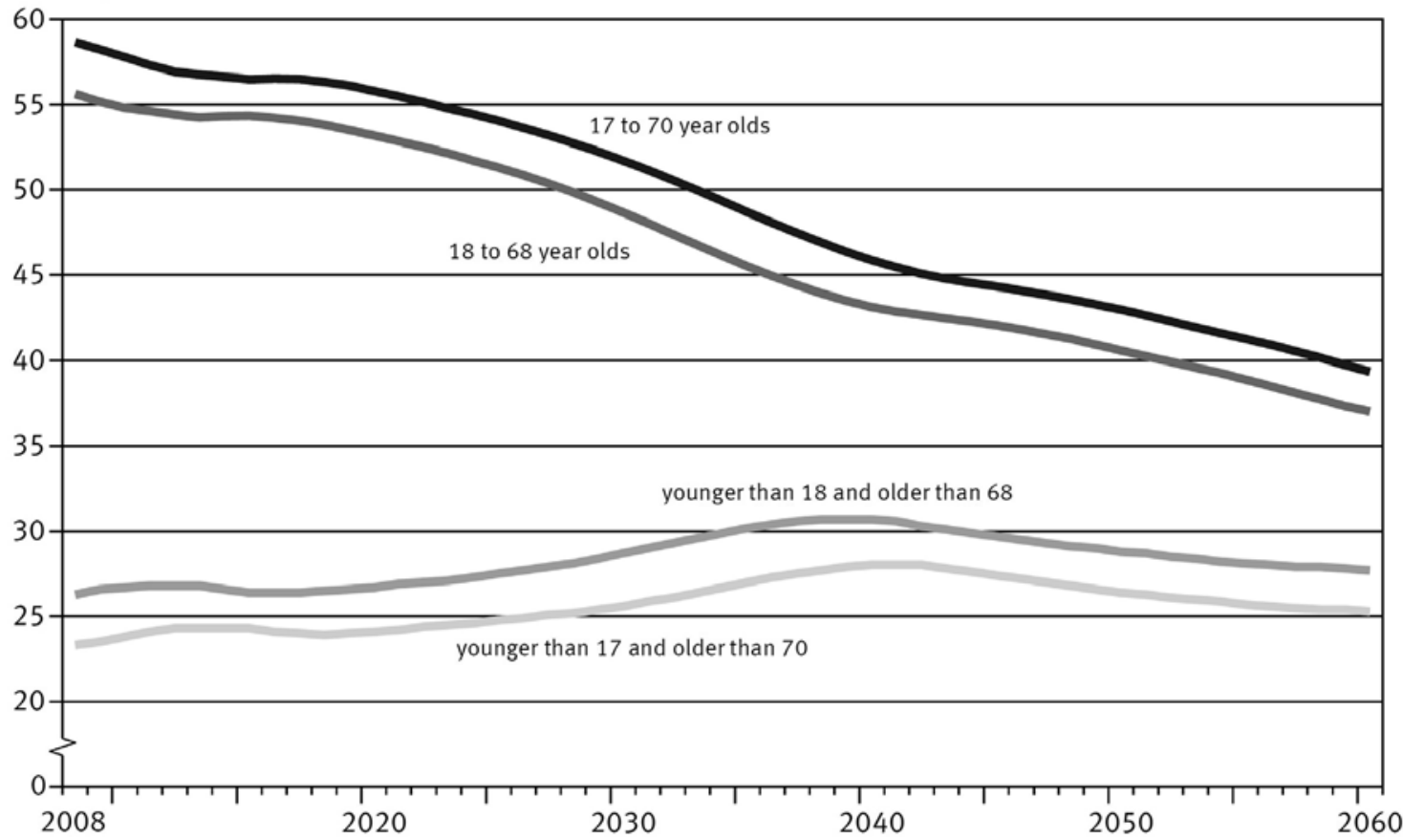

Table 4. Ratio of the population of blood donation age to the total population and to people outside the age bracket*

\begin{tabular}{|c|c|c|c|c|}
\hline & \multicolumn{2}{|c|}{ Share in the total population; \% } & \multicolumn{2}{|c|}{ Per 100 persons outside the age bracket } \\
\hline & $\begin{array}{l}\text { 18- to } 68 \text {-year- } \\
\text { olds }\end{array}$ & $\begin{array}{l}17 \text { - to } 70 \text {-year- } \\
\text { olds }\end{array}$ & $\begin{array}{l}\text { 18- to } 68 \text {-year- } \\
\text { olds }\end{array}$ & $\begin{array}{l}\text { 17- to } 70 \text {-year- } \\
\text { olds }\end{array}$ \\
\hline 2008 & 68 & 72 & 211 & 252 \\
\hline 2015 & 67 & 70 & 205 & 232 \\
\hline 2020 & 67 & 70 & 199 & 232 \\
\hline 2025 & 65 & 69 & 187 & 218 \\
\hline 2030 & 63 & 67 & 170 & 202 \\
\hline 2035 & 60 & 64 & 151 & 180 \\
\hline 2040 & 58 & 62 & 141 & 164 \\
\hline 2045 & 59 & 62 & 142 & 162 \\
\hline 2050 & 58 & 62 & 141 & 163 \\
\hline 2055 & 58 & 62 & 138 & 160 \\
\hline 2060 & 57 & 61 & 134 & 155 \\
\hline
\end{tabular}

*From 2015 results of the 12th coordinated population projection, variant 1-W1 ('medium' population, lower limit).
The relation between the age group of potential blood donors and that of people who have not yet reached or have exceeded the relevant age bracket will change in the future (fig. 5). The size of the second group which can be exclusively regarded as a group of potential recipients will increase especially by the end of the 2030s. The reason is that the large 1960s birth cohorts will move into older age. Between 2008 and 2040, the number of people who are older than 68 or 70 years will rise by more than $40 \%$. As the following birth cohorts of the 1970s and 1980s will be by far smaller and the number of those aged under 17 or 18 years will decline too, the two groups (of persons in and persons outside the age bracket for blood donation) will follow a similar (declining) trend after 2040.

Due to the above trends, the share of the population of blood donation age in the total population will fall especially rapidly until 2040 , i.e. from currently about $70 \%$ by some 10 percentage points (table 4). The number of people of blood donation age per 100 persons who are not in the age brackets defined (too young or too old) will decline correspondingly. In 2008, the number totalled 211 for the age bracket of 18 to 68 years while it was 252 for the age bracket of 17 to 70 years. In 2040, it will amount to not more than 141 or 164 . However, this relation will only be subject to slight changes between 2040 and 2060 . 


\section{Conclusions}

The results of the 12th coordinated population projection reveal the following in relation to the age groups of potential blood donors: The total of potential blood donors will decline in absolute and relative terms (related to the total population and the age group of 'non-donors'). This applies to both the age group of 18 to 68 years and the age group of 17 to 70 years. The sizes of both age groups of potential blood donors will shrink at a similarly rapid rate. However, shifting the age bracket from between 18 and 68 years to between 17 and 70 years would temporarily relieve the situation. Until the early 2020s, the population aged 17 to 70 years will comprise at least as many people as the current age group of the 18- to 68 -year-olds. A higher level of net migration, too, would slow down the shrinking of the age group of potential blood donors. This effect would become noticeable especially in the early 2040s. Until 2040, the development of the group of po- tential blood donors would be particularly beneficial if the age bracket were 17 to 70 years. In the period between 2040 and 2060 , the age group of 18- to 68-year-olds will be larger under the assumption of an annual net migration of 200,000 than the age group of 17- to 70-year-olds under the assumption of an annual net migration of 100,000 . The potential positive effect of migration on recruitment of blood donors is very hypothetical. The current experiences show that it is quite hard to recruit new blood donors from immigrants, especially from firstgeneration immigrants and from immigrants with insufficient knowledge of local native language. Therefore, to use the additional potential donor resource created by immigrants, it is necessary to adapt recruitment strategies appropriately.

\section{Disclosure}

The authors declared no conflict of interest.

\section{References}

1 Federal Statistical Office: Germany's Population by 2060 - Results of the 12th Coordinated Population Projection. Wiesbaden, Statistisches Bundesamt, 2009.

2 Willekens FJ: Demographic forecasting: state-ofthe-art and research needs; in Hazeu CA, Frinking GAB (eds): Emerging Issues in Demographic Research. Amsterdam, Elsevier, 1990, pp 9-66.

3 Flaskämper, P: Bevölkerungsstatistik, Hamburg, Verlag Richard Meiner, 1962
4 Pötzsch O: Annahmen zur Geburtenentwicklung in der 12. koordinierten Bevölkerungsvorausberechnung; in Wirtschaft und Statistik 1/2010. Wiesbaden, Statistisches Bundesamt, 2010. www.destatis. de/jetspeed/portal/cms/Sites/destatis/Internet/DE/ Content/Publikationen/Querschnittsveroeffentlichungen/WirtschaftStatistik/Bevoelkerung/Geburte nentwicklung12010,property=file.pdf.

5 Bomsdorf E, Trimborn M: Sterbetafel 2000. Modellrechnungen der Sterbetafel, in: Zeitschrift für die gesamte Versicherungswissenschaft 1992;81: $457-485$.
6 Federal Statistical Office: Germany's Population by 2050 . Results of the 11th Coordinated Population Projection, Wiesbaden, Statistisches Bundesamt, 2006, pp 36-40.

7 Coleman D: The demographic effects of international migration in Europe, Oxford Rev Econ Policy 2008;24(3):452-476.

8 Warner K, Ehrhart C, de Sherbinin A., Adamo S, Chai-Onn T: In Search of Shelter. Mapping the Effects of Climate Change on Human Migration and Displacement, Online J 2009. www.careclimatechange. org or http://ciesin.columbia.edu/publications.html. 